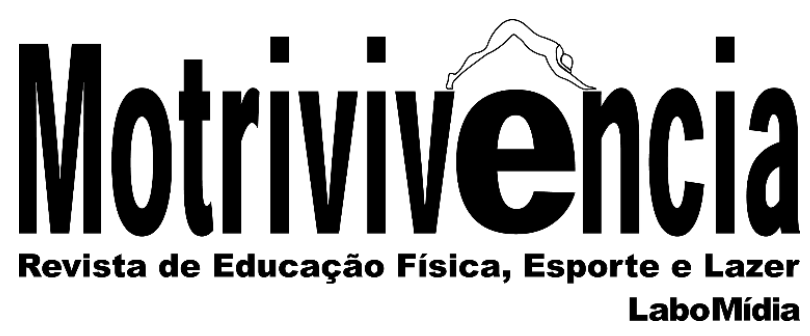

Apresentação da Seção Temática

\title{
Políticas públicas de Educação Física, esporte, saúde e lazer: os grupos de pesquisa e a produção do conhecimento
}

\begin{abstract}
RESUMO
Este texto tem por objetivo apresentar e justificar a sessão temática "Grupos de Políticas Públicas de Educação Física, Esporte, Saúde e Lazer" promovida pelo Grupo de Trabalho Temático em Políticas Públicas do Colégio Brasileiro de Ciências do Esporte. A sessão temática conta com 9 artigos, tendo a participação de grupos das 5 regiões brasileiras, além da presença de texto de outro país da América Latina e Caribe. Os textos possibilitam conhecer os grupos de pesquisa, bem como suas produções do conhecimento.
\end{abstract}

PALAVRAS-CHAVE: Políticas públicas; Educação física; Esporte e lazer; Grupos de pesquisa; Produção do conhecimento.
Fernando Henrique Silva Carneiro (*)

Doutor em Educação Física

(Universidade de Brasília)

Professor do Instituto Federal Goiás, campus Inhumas, Goiânia, Brasil fernandohenriquesc@gmail.com

Marcelo de Paula Melo (*)

Doutor em Serviço Social

(Universidade Federal do Rio de Janeiro) Professor da Universidade Federal do Rio de Janeiro, Rio de Janeiro, Brasil marcelaomelo@gmail.com

(*) Os autores integram o Comitê Científico do GTT Políticas Públicas do CBCE e exerceram a função de editores associados dessa Seção Temática. 


\title{
Public policies on Physical Education, sport, health and leisure: research groups and knowledge production
}

\begin{abstract}
This text aims to present and justify the thematic session "Public Policy Groups of Physical Education, Sports, Health and Leisure" promoted by the Thematic Working Group on Public Policies of the Colégio Brasileiro de Ciências do Esporte. The thematic session has 9 articles, with the participation of groups from the 5 Brazilian regions, in addition to the presence of text from another country in Latin America and the Caribbean. The texts make it possible to get to know the research groups, as well as their knowledge production.

KEYWORDS: Public policies; Physical education; Sports and leisure; Research groups; Knowledge production
\end{abstract}

Políticas públicas de Educación Física, deporte, salud y ócio: grupos de investigación y producción de conocimiento

\section{RESUMEN}

Este texto tiene como objetivo presentar y justificar la sesión temática "Grupos de Políticas Públicas de Educación Física, Deporte, Salud y Ocio" promovida por el Grupo de Trabajo Temático de Políticas Públicas del Colégio Brasileiro de Ciências do Esporte. La sesión temática consta de 9 artículos, con la participación de grupos de las 5 regiones brasileñas, además de la presencia de textos de otro país de América Latina y el Caribe. Los textos permiten conocer a los grupos de investigación, así como su producción de conocimiento.

PALABRAS-CLAVE: Políticas públicas; Educación física; Deportes y ócio; Grupos de investigación; Producción de conocimiento 


\section{INTRODUÇÃO}

O Colégio Brasileiro de Ciências do Esporte (CBCE), entidade científica que congrega pesquisadores/as ligados/as à área de Educação Física/Ciências do Esporte, foi criado em 1978. Sua organização se dá a partir de Secretarias Estaduais e Grupos de Trabalhos Temáticos (GTTs), liderados por uma Direção Nacional. O GTT de Políticas Públicas do CBCE foi criado em 1997, por ocasião da realização do X Congresso Brasileiro de Ciências do Esporte (CONBRACE) realizado na cidade de Goiânia-GO. Atualmente o GTT de Políticas Públicas do CBCE conta com a seguinte ementa:

Estudos dos processos de formulação, adoção e avaliação das políticas públicas de Educação Física, Esporte e Lazer. Estudos das concepções, princípios e metodologias de investigação adotados na consecução de políticas públicas, voltados para a apreensão da produção de bens e serviços públicos relativos à Educação Física, Esporte e Lazer. (CBCE, 2021, s. p.) $)^{1}$

Ao longo de sua trajetória, o GTT de Políticas Públicas do CBCE tem vivido um processo de consolidação e diversificação das pesquisas, já tendo, essa produção, sido objeto de estudos variados que buscaram analisar a produção do conhecimento do referido GTT (HÚNGARO et al., 2009; AMARAL; PEREIRA, 2009; STAREPRAVO, 2011). De acordo com Starepravo (2011, p. 168), “O principal fórum de discussão sobre políticas públicas de esporte e lazer, o GTT de Políticas Públicas do CBCE mostrou o avanço quantitativo na área, materializado no aumento de produção científica circulante no grupo, especialmente quando da realização dos CONBRACES.”

Esse processo fez com que a atual composição do GTT de Políticas Públicas do CBCE propusesse a realização de um dossiê com trabalhos sobre a temática "Grupos de Políticas Públicas de Educação Física, Esporte, Saúde e Lazer". Com isso, esperamos aumentar a visibilidade aos diferentes grupos existentes no país - e até no continente - acerca dos estudos em Políticas Públicas de Educação Física, Esporte, Saúde e Lazer. Os grupos de pesquisa são espaços importantes para formação dos/as pesquisadores/as, bem como fundamentais para a produção do conhecimento científico. Dessarte, apreender e apresentar alguns desses grupos é uma tarefa de relevo ao campo.

Assim, foi realizado contato com os editores da Revista Motrivivência para que acolhessem a publicação da referida sessão temática em meados de 2020. A escolha por esta revista se deu por

\footnotetext{
${ }^{1}$ Disponível em: http://www.cbce.org.br/gtt/gtt12-politicaspublicas
} 
ser um dos principais periódicos da área de Educação Física/Ciências do Esporte e também pelo seu posicionamento crítico explícito de compreensão da realidade para transformá-la, elemento que pode ser visto em editoriais publicados nos últimos anos (SILVA; PIRES; PEREIRA, 2021, 2020, 2019).

Em meados de 2020 iniciou-se o processo de divulgação, convidando os diferentes grupos de pesquisa que tematizam Políticas Públicas de Educação Física, Esporte, Saúde e Lazer. A proposta de ementa construída coletivamente pelo GTT de Políticas Púbicas do CBCE apontava que

A publicação pode ser desenvolvida a partir de diferentes possibilidades, como a realização de balanço sobre as políticas públicas de Educação Física, Esporte, Saúde e Lazer no Brasil e na América Latina e Caribe a partir dos referenciais teóricos utilizados pelos grupos. A busca é por produções coletivas que demonstrem aquilo que foi e vem sendo desenvolvido pelos diferentes grupos de pesquisa envolvidos na temática.

A partir do convite realizado, recebemos 17 artigos para a sessão temática. Contudo, 8 deles foram rejeitados por não cumprirem o escopo da proposta, havendo a aprovação de 9 artigos. A expectativa prévia de que grupos de pesquisa das 5 regiões brasileiras, e a presença de texto de outro país da América Latina e Caribe, foi alcançada. Destarte, contar com essa diversidade regional das produções submetidas e aprovadas demonstra a busca por capilaridade e articulação que o GTT de Políticas Públicas do CBCE tem buscado implantar ao longo das suas gestões. A seguir passamos a apresentar os 9 textos que compõem a sessão temática.

Da região norte, representando a Universidade Federal do Acre, há o texto intitulado "Produção de conhecimento do grupo de pesquisa "LEPEF-EdsaLa" em políticas públicas de esporte e lazer no estado do Acre" que buscou apresentar a produção do conhecimento do Grupo de Pesquisa LEPEF-EdSaLa, situando esta temática em nível estadual, via Rede Cedes/CDPPEL-Acre.

Da região nordeste há 3 textos, o primeiro deles tem como título "Políticas públicas de esporte e lazer: um balanço crítico da produção científica no Maranhão", vinculado à Universidade Federal do Maranhão, empreendeu investigação sobre a trajetória do GEPPEF/UFMA na área das políticas públicas de esporte e lazer, realizando um balanço crítico da sua produção científica. Da Universidade Estadual do Sudoeste da Bahia há o texto "Centro de Estudos em Política e Gestão do Esporte e Lazer: trajetória científica e perspectivas futuras” que discute sobre a produção científica do grupo, bem como reflete sobre perspectivas futuras de investigação. "Contemplar: a trajetória de um coletivo no fomento da pesquisa, extensão e cidadania para o lazer" é o texto da Universidade 
Federal do Delta do Parnaíba que que procurou trazer à tona a trajetória do grupo em relação a sua produção do conhecimento e suas atividades de extensão.

Da região centro-oeste há o texto "Avante! 10 anos de um caminho se faz caminhando..." que discutiu a trajetória do grupo Avante da Universidade de Brasília a partir da dimensão histórica, da abordagem teórico-metodológica e da agenda de pesquisa. Da região sul há a produção intitulada "Grupo de estudos e pesquisa em políticas de esporte e lazer (GEPPOL/UEM): uma década de contribuições Científico/Acadêmicas" que procurou socializar as ações do GEPPOL no que tange as pesquisas sobre políticas públicas de esporte e lazer, sendo ele um grupo da Universidade Estadual de Maringá.

Da região sudeste há duas produções compondo a sessão temática, o primeiro é o texto intitulado "Produção científica e contribuições do Grupo de Estudos e Pesquisa em Políticas Públicas e Lazer (GEP3L) da Unicamp” cuja vinculação se dá com a Universidade Estadual de Campinas, tendo buscado descrever e analisar o processo de desenvolvimento e a produção do GEP3L. "Modelos e abordagens de implementação para a análise de políticas de esporte e lazer: construção do Grupo de Pesquisa Polis/NeoPolis" é a outra produção da região localizada na Universidade Federal de Minas Gerais cujo objetivo foi apresentar o grupo de pesquisa Polis/NeoPolis e refletir sobre a literatura do campo das políticas públicas que tem fundamentado seus trabalhos e publicações na área do esporte e lazer.

Por último, mas não menos importante, há o texto da Argentina com o título "Linhas de pesquisa em políticas públicas na República Argentina: esportes sob a órbita de governos populares e neoliberais" representando a Universidad Nacional de La Plata, ele buscou refletir sobre os temas desenvolvidos e as linhas de pesquisa referente as políticas públicas de esporte e recreação.

Como pode ser verificado, todos os textos publicados na sessão temática se referem à grupos de pesquisa situados em Universidades públicas, apontando que este tem sido o lugar privilegiado de formação dos pesquisadores/as e de produção do conhecimento sobre as Políticas Públicas de Educação Física, Esporte, Saúde e Lazer. Assim, é preciso continuar defendendo a ciência e as Universidades públicas, sobretudo no atual contexto de negacionismo científicos e obscurantismo que tem sido a marca do atual governo federal. Fazer essa defesa nos coloca frontalmente contra os processos ultraneoliberais, neofacistas e de genocídio que tem assolado a população brasileira e nos coloca para continuar lutando por um outro projeto societário em que todos e todas possam estar vivos/as para acessar como direito social os diferentes bens sociais, dentre eles a Educação Física, o Esporte e o Lazer. 


\section{REFERÊNCIAS}

AMARAL, Silvia Cristina Franco; PEREIRA, Ana Paula Cunha. Reflexões sobre a produção em políticas públicas de Educação Física, esporte e lazer. Revista Brasileira de Ciências do Esporte. v. 31, n. 1. Campinas: Autores Associados, 2009. Disponível em: http://revista.cbce.org.br/index.php/RBCE/article/view/631

CBCE. GTT 12 - Políticas Públicas. 2021. Disponível em: http://cbce.org.br/gtt/gtt12politicaspublicas. Acesso em: 04 mai. 2021.

HÚNGARO, Edson Marcelo et al. Balanço inicial da produção do GTT de políticas públicas do CBCE (1997-2005): avanços, ausências e perspectivas. In: HÚNGARO, E. M.; SOUZA, W. L. L. de (org.). Cultura, educação, lazer e esporte: fundamentos, balanços e anotações críticas. Santo André: Alpharrabio, 2009, p. 93-124.

SILVA, Mauricio Roberto; PIRES, Giovani Lorenzi; PEREIRA, Rogério Santos. "Quero ter olhos pra ver a maldade desaparecer”! Fora, Bolsonaro! Impeachment, desde sempre e já! Motrivivência, Florianópolis, v. 3, n. 64, p. 01-13, 2021. Disponível em:

https://periodicos.ufsc.br/index.php/motrivivencia/article/view/79503 DOI:

https://oi.org/10.5007/2175-8042.2021e79503

SILVA, Mauricio Roberto; PIRES, Giovani Lorenzi; PEREIRA, Rogério Santos. Bolsonaro e a COVID-19: e daí? "o Brazil tá matando o Brasil”, "do Brasil, SOS ao Brasil”, "chora a nossa pátria, mãe gentil...”. Motrivivência, Florianópolis, v. 32, n. 62, p. 01-19, abr.jun., 2020. Disponível em: https://periodicos.ufsc.br/index.php/motrivivencia/issue/view/3101 DOI https://doi.org/10.5007/2175-8042.2020e74507

SILVA, Mauricio Roberto; PIRES, Giovani Lorenzi; PEREIRA, Rogério Santos. Manifesto contra o neoliberalismo totalitário, a destruição da educação, do meio ambiente, da ciência, da cultura e do ministério do esporte no governo Bolsonaro. E pelo chi, chi, chi, lê, lê, lê!!! Motrivivência, Florianópolis, v. 31, n. 60, p. 01-18, set./dez., 2019. Disponível em:

https://periodicos.ufsc.br/index.php/motrivivencia/article/view/2175-8042.2019e69869 DOI https://doi.org/10.5007/2175-8042.2019e69869

STAREPRAVO, Fernando Augusto. Políticas públicas de esporte e lazer: aproximações, intersecções, rupturas, e distanciamentos entre os subcampos político/burocrático e cientifico/acadêmico. Tese (Doutorado em Educação Física) - Universidade Federal do Paraná, Curitiba 2011. 